\title{
Coalification by Clay-Catalyzed Oligomerization of Plant
}

\section{Monomers.}

April 1, 1990 to June 30, 1990

Grant No. : DE-FGJ22-88PC88931

JANO

Milton Orchin and R. Marshall Wilson

Department of Chemistry, University of Cincinnati

Cincinnati, Ohio 45221-017?

During this reporting period, we have continued with our study of the chemistry of $\mathrm{C}_{6}-\mathrm{C}_{3}$ plant monomers with montmorillonite clay $(\mathrm{K}-10)$. In this block of the research, we have examined the reaction of $\mathrm{K}-10$ with methyleugenol (1, Scheme 1). Here again the indane dimers 2 and 3 were observed. These same two dimers are formed in the reaction of $\mathrm{K}-10$ with methylisoeugenol (4), see previous progress reports. Consequently, it seems likely that 1 is isomerized to 4 in the acidic environment of the $\mathrm{K}$ 10. Of particular interest in this reaction are the two new dimers 5 and 6. The structure of the anthracene dimer 6 has been confirmed by comparison of its ultraviolet spectrum with that of the dimethyl analog 7, kindly provided by A. W. Czarnik of Ohio State University. No comparable dimers have been observed in the dimerizations of 4 . In light of the equilibration between 1 and 4 under these reaction conditions, it seems likely that 5 and 6 arise from cations involved in this isomerization as outlined in Scheme 2. Thus, the cation 8 derived from the protonation of 4 might be formed through either of the pathways shown in Scheme 2 . 
Addition of 1 to 8 should lead to the dimer 9 which in turn might be protonated to form cation 10. This cation might react by either of two
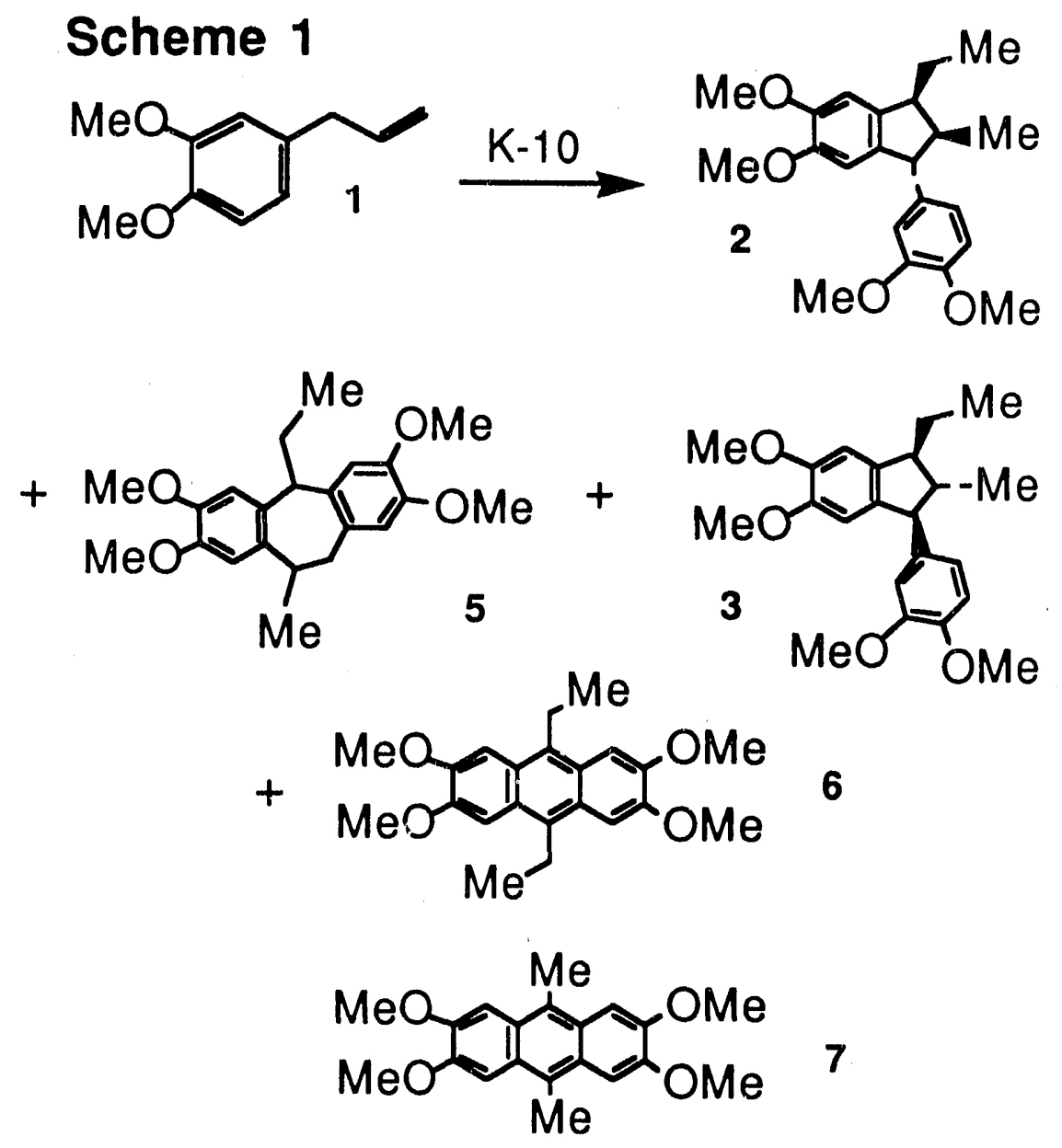

pathways. Pathway a would lead to the dibenzocycloheptadiene 5 . Alternatively, in pathway $\mathbf{b}$, a hydride shift followed by cyclization would lead to the anthracene 6 following loss of a proton and oxidation. At the present time, there are three unidentified products in this reaction mixture. If one of these should prove to be the dimer 9, this would lend significant support to the mechanism proposed in Scheme 2. Finally, while 


\section{Scheme 2}

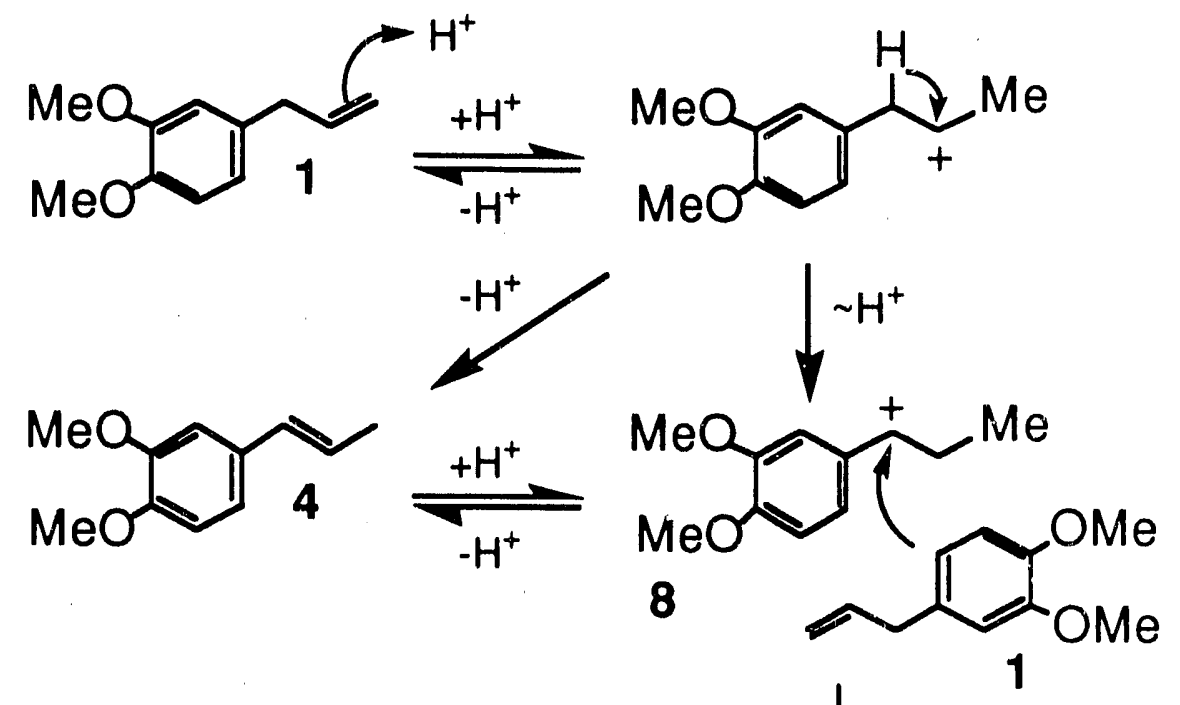

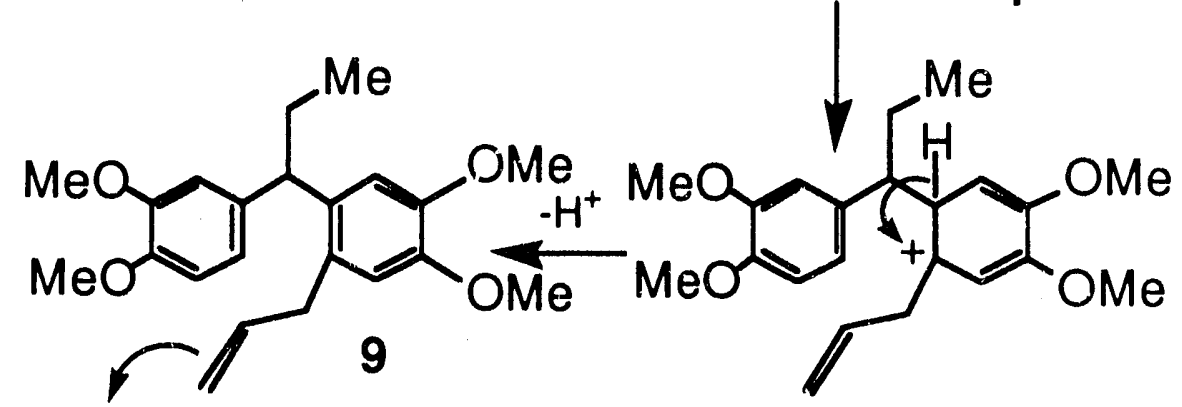

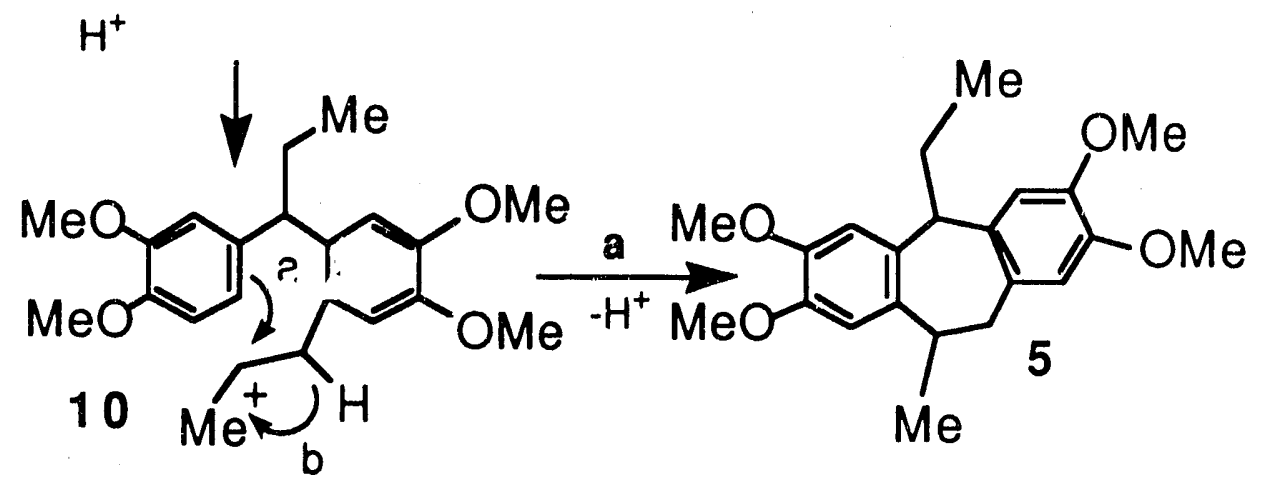

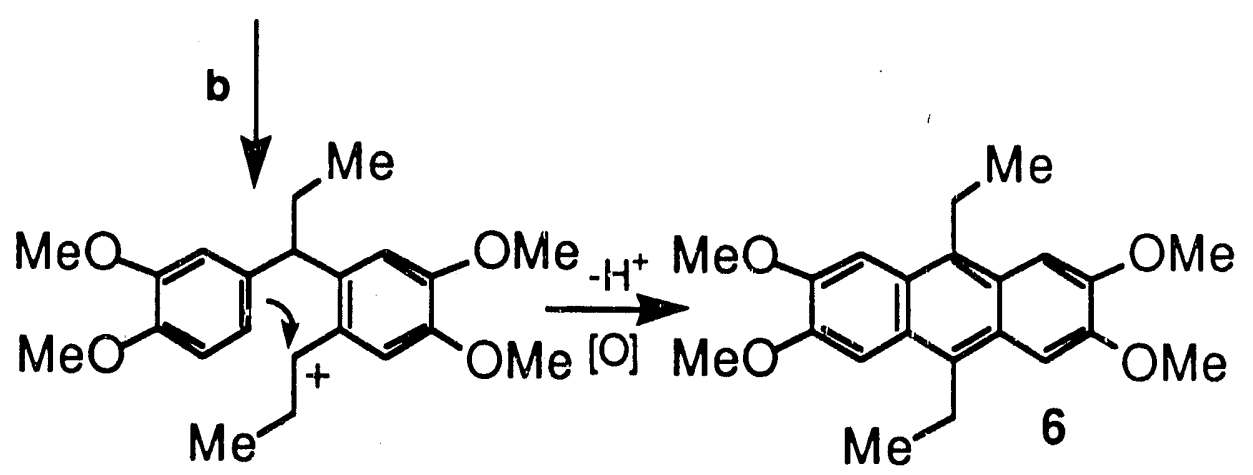


no presently known, naturally occurring lignans or lignins have structures related to 5 and $\mathbf{6}$, the formation of at least the anthracene ring system from 1 may be of significance, since anthracene units are known to occur in coal.related to 5 and 6 , the formation of at least the anthracene ring system from 1 may be of significance, since anthracene units are known to occur in coal.

Scheme 3
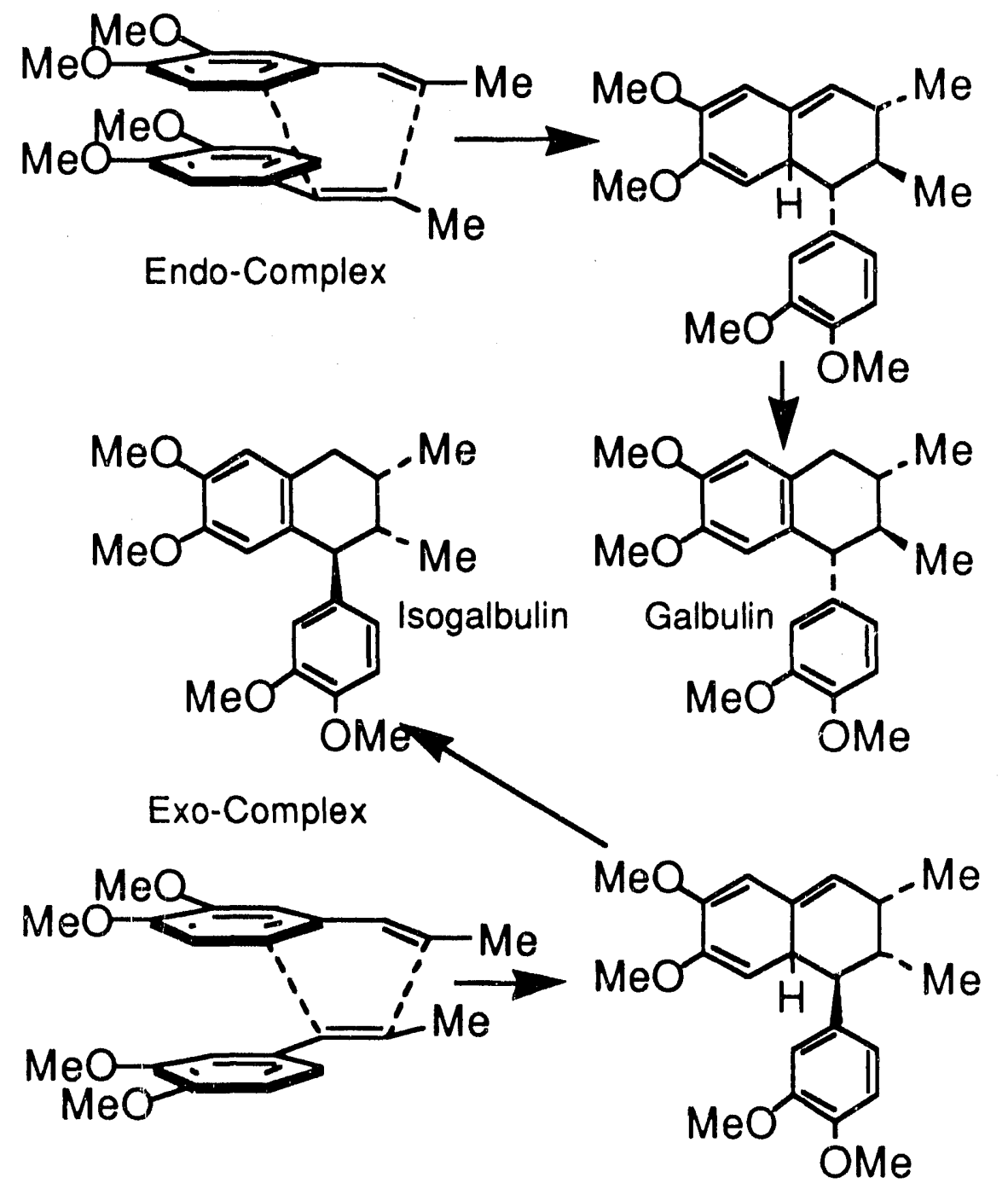

In yet another block of research associated with our interest in methods for the dimerization of $\mathbf{4}$, we have examined the photochemistry of 4. The original question that lead us into this area of lignan chemistry 
was whether 4 might be induced to undergo Diels-Alder dimerizations to form the natural products galbulin or isogalbulin as outlined in Scheme 3 .. While this type of general reaction does occur via a radical cation mechanism as shown in Scheme 4, galbulin or isogalbulin themselves have Scheme 4

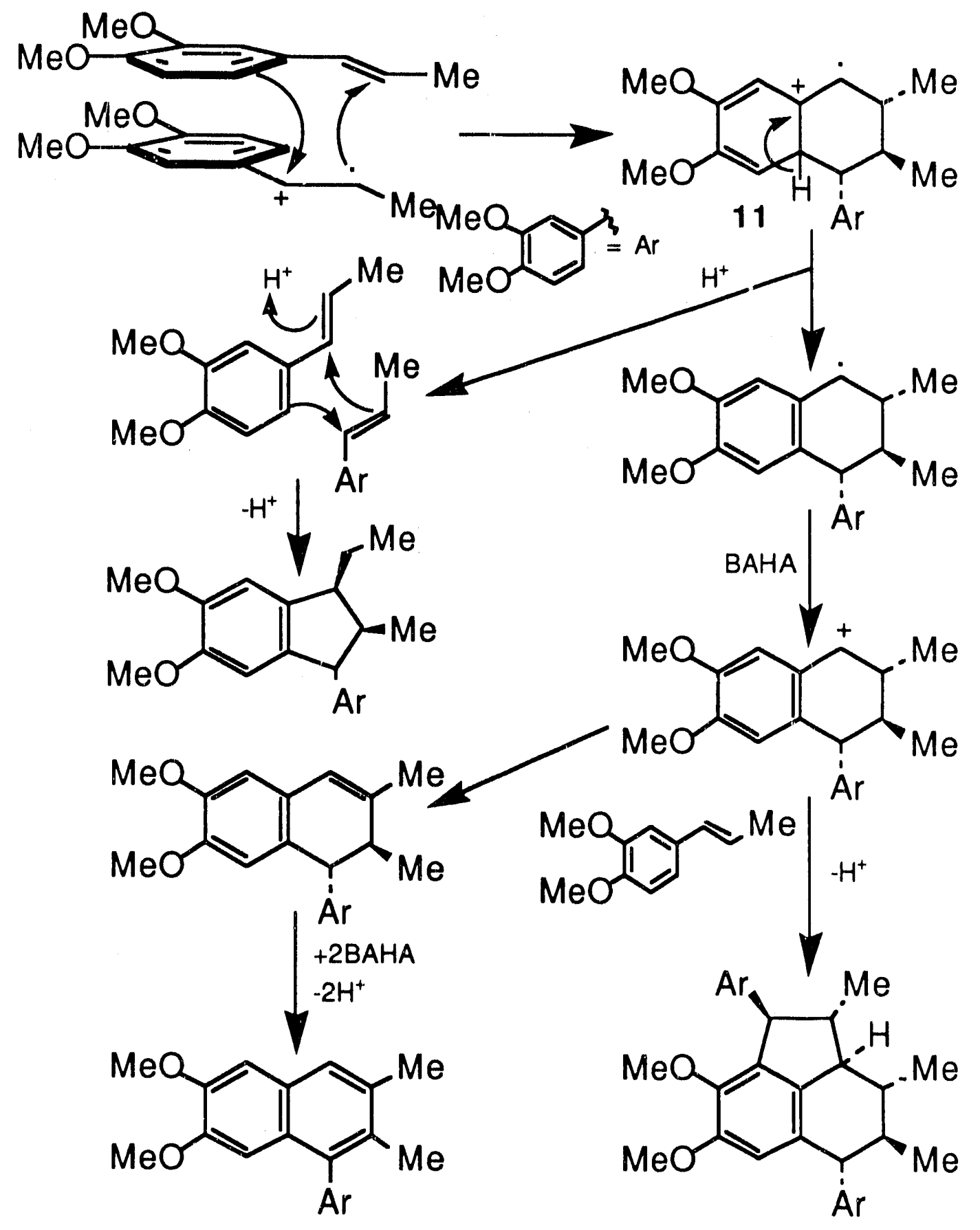


never been isolated from these radical cation reactions. In order for these natural products to be formed in this type of radical cation Diels-Alder reaction, the radical cation 11 would have to be quenched by a reverse electron transfer. Apparently, this does not occur and the pathways shown in Scheme 4 occur instead, as has been described in our previous reports. Therefore, we were both surprised and pleased to observe that galbulin is formed upon the direct irradiation of 4 along with the other products shown in Scheme 5. The presence of galbulin in this reaction has been

\section{Scheme 5}<smiles>C/C=C/c1ccc(OC)c(OC)c1</smiles>
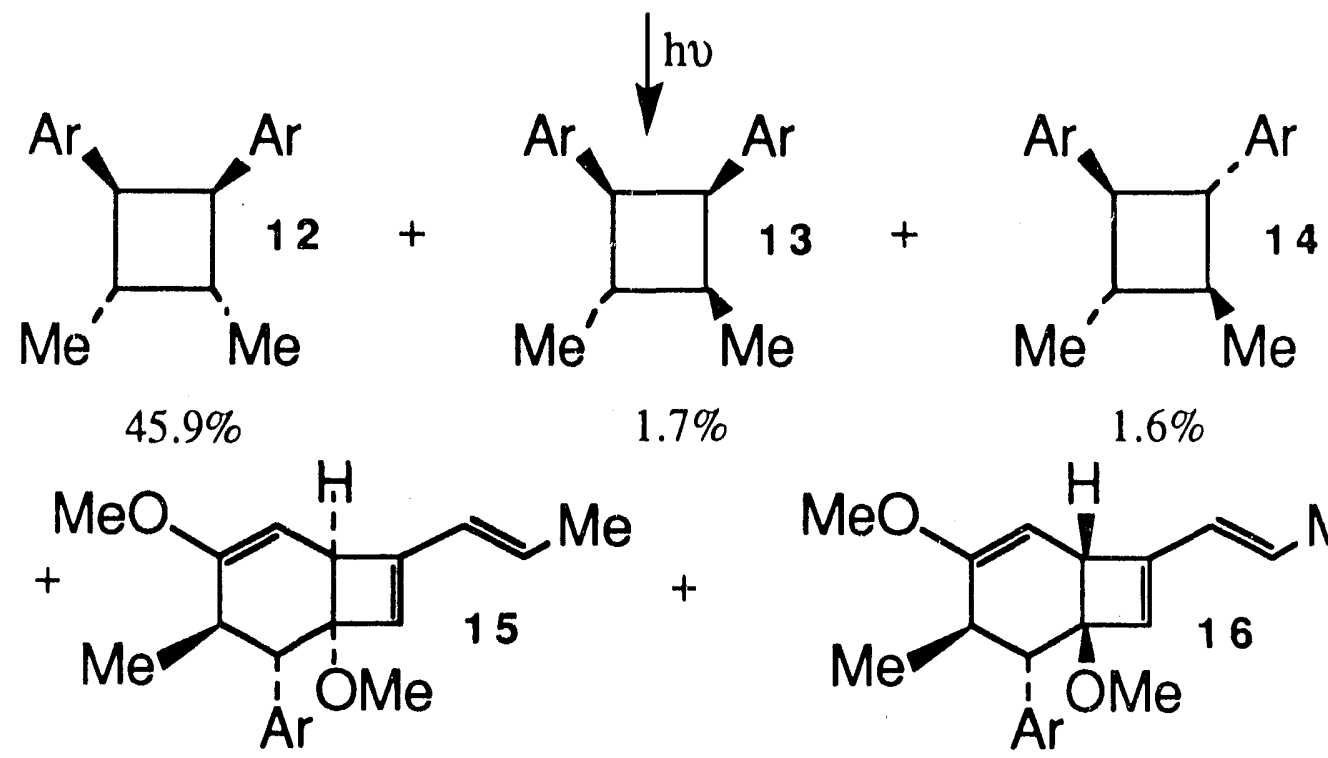

$1.7 \%$

$1.6 \%$

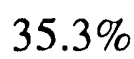<smiles>COc1cc2c(cc1OC)[C@H](Br)C([14CH3])[C@@H](C)C2</smiles>

$13.6 \%$

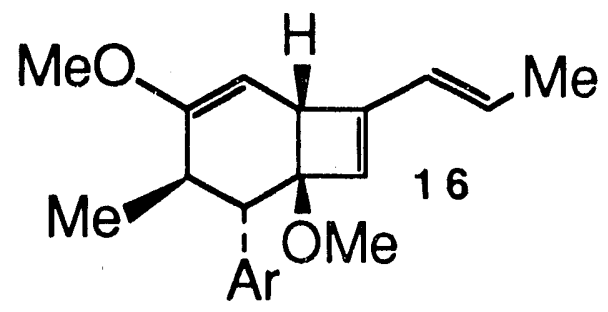

$0.8 \%$ 
confirmed by comparison with an authentic sample. Unfortunately, it is formed in very low yield, and this photochemical route can have very littie relevance to the possible occurrence of aryltetralin units in coal. Nevertheless, it may have some relevance to the production of galbulin in the living plant.

Even though this reaction would seem to have little relevance to the main objectives of this project, several of the products isolated from this reaction are quite novel and deserve comment. While we have not conducted a detailed mechanistic study of this reaction, we have noted that these products are only formed with neat 4 or in very concentrated solutions of 4. This would seem to imply that most of these products are of singlet origin.

It is also interesting to note that with the exception of 13 and 14 , these products all seem to be derived from quite crowded transition states. Thus, for example, the most hindered cyclobutane $\mathbf{1 2}$ is formed in about 29 times higher yield than the less hindered cyclobutane 14. This is probably indicative of the intermediacy of excimers which would be stabilized by maximum overlap. The relationship between these products and their corresponding putative excimers is shown in Scheme 6. As can be seen from these drawings, the geometry leading to 12 is the most hindered possible configuration. Whereas, that leading to 14 is one of the least hindered configurations possible. This same empirical correlation seems to extend to the formation of galbulin as well. The most hindered geometry for a concerted reaction (symmetry forbidden) leads to galbulin. While the less hindered geometry for a concerted reaction should produce 


\section{Scheme 6}
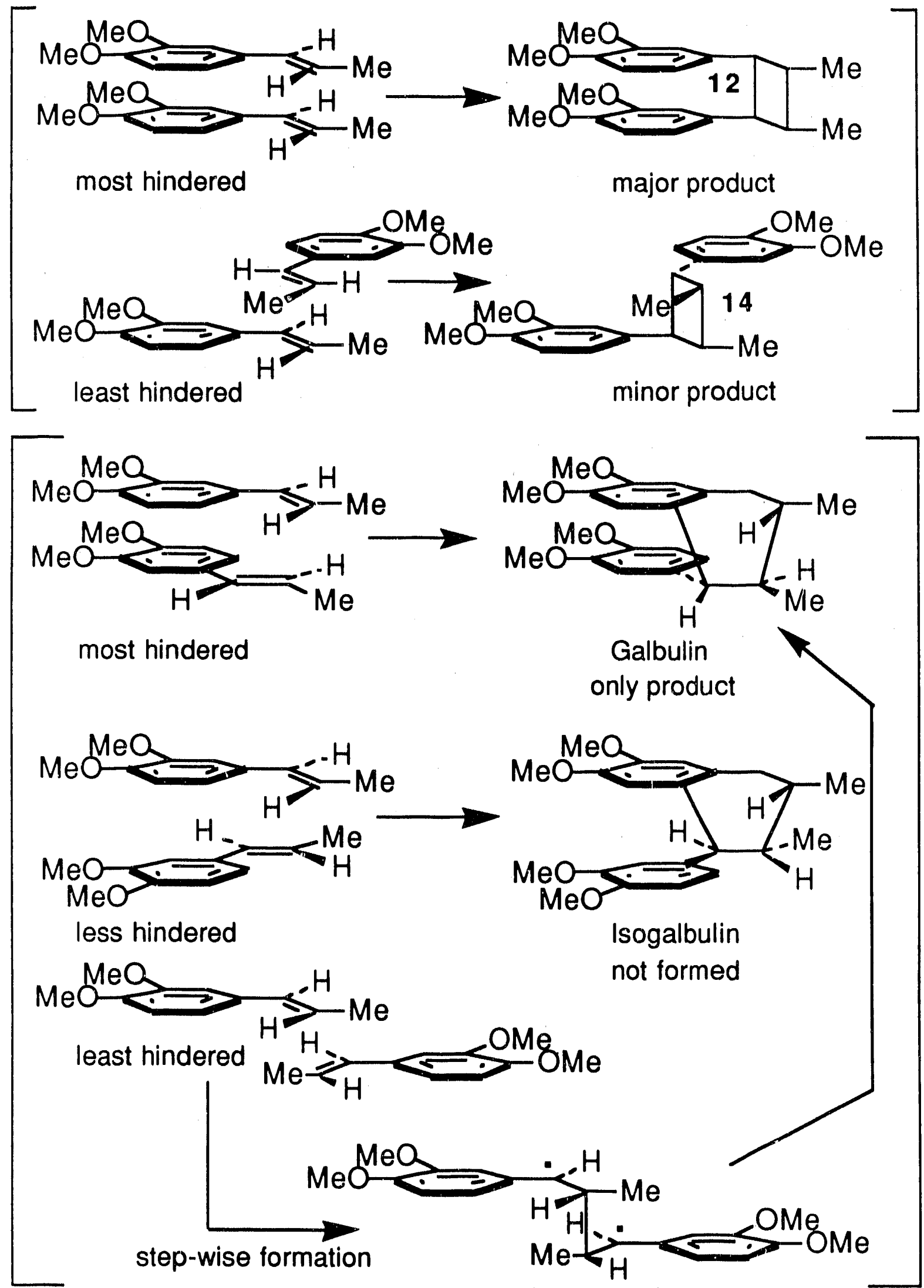


\section{Scheme 6 cont'd}

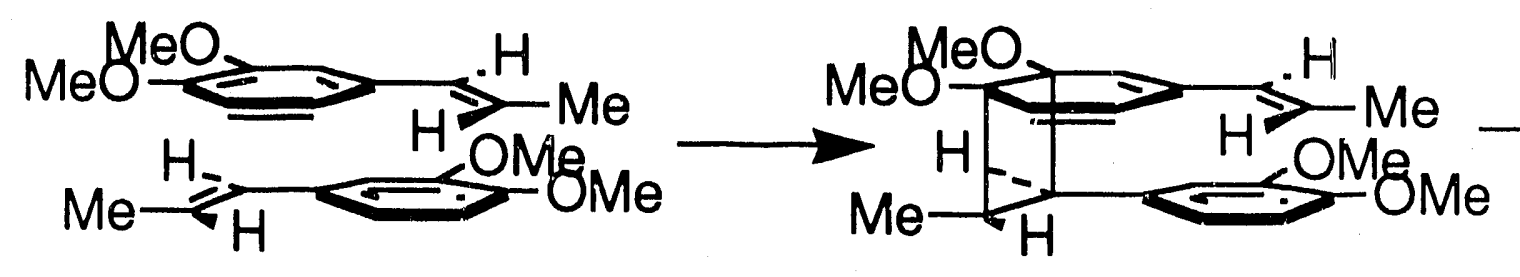

more hindered

less hindered

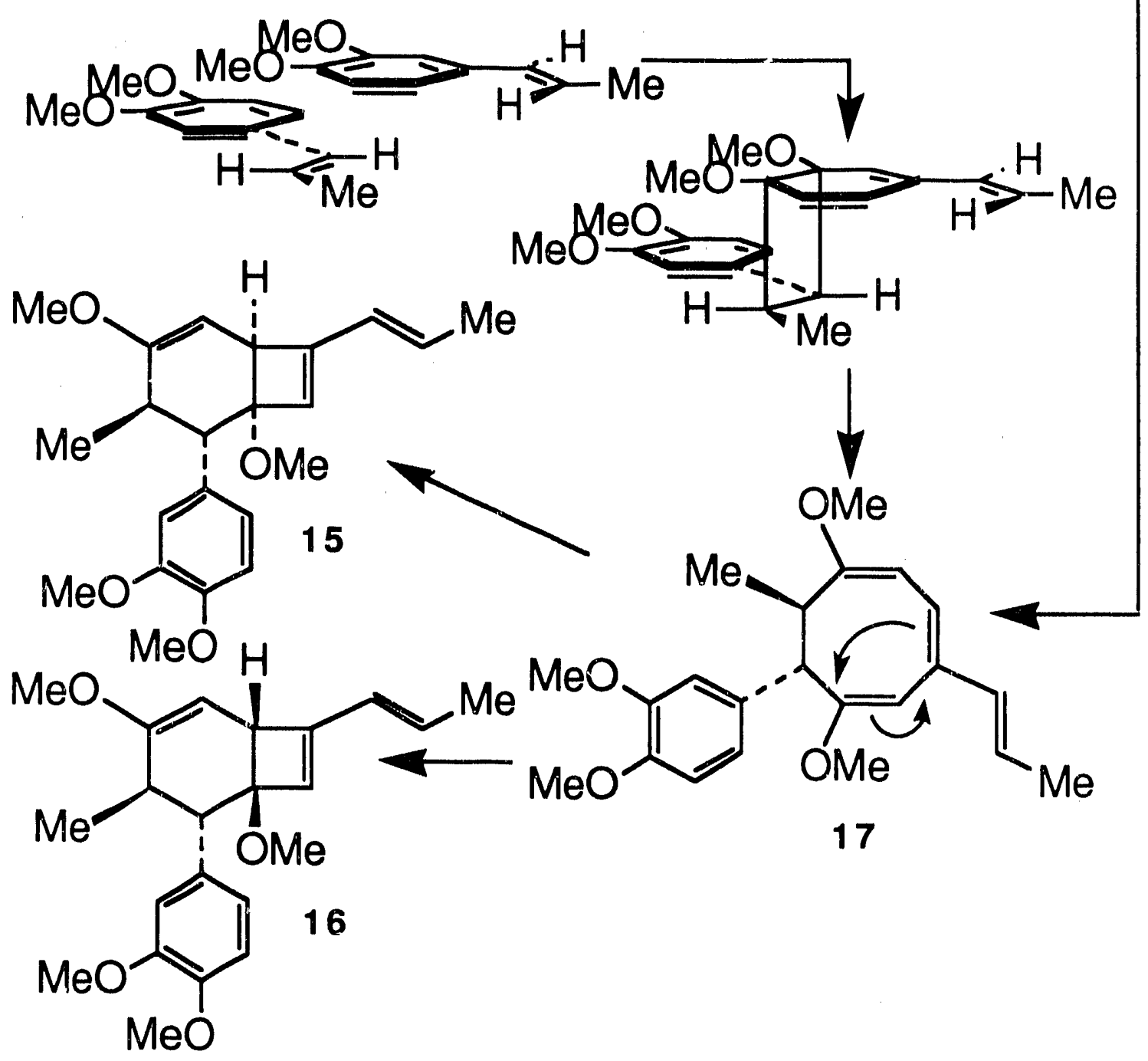

isogalbulin, this isomer was not detected. However, if the reaction occurs via a step-wise process, the least crowrled configuration for coupling the two molecules of 4 should produce galbulin. Therefore, it is quite possible 
that galbulin is formed via a nonconcerted process. Finally the formation of the two bicyclo[4.2.0]octadiene isomers 15 and 16 requires a cycloaddition at the most congested site on the benzene ring, the bond between the two methoxy groups. Unfortunately, the stereochemistry of the initially formed cyclobutane is lost during the electrocyclic ringopening to form 17. So it is not possible to determine whether this reaction proceeds through the more or the less hindered reaction geometry.

In summary, this photoreaction seems to involve tight complexes which are insensitive to steric crowding. Furthermore, since this photochemical method constitutes the simplest synthesis of galbulin, a better understanding of the factors which govern the relative stabilities of these complexes might be useful in the rational design of lignan synthetic strategies.

\section{DISCLAIMER}

\footnotetext{
This report was prepared as an account of work sponsored by an agency of the United States Government. Neither the United States Government nor any agency thereof, nor any of their employees, makes any warranty, express or implied, or assumes any legal liability or responsibility for the accuracy, completeness, or usefulness of any information, apparatus, product, or process disclosed, or represents that its use would not infringe privately owned rights. Reference herein to any specific commercial product, process, or service by trade name, trademark, manufacturer, or otherwise does not necessarily constitute or imply its endorsement, recommendation, or favoring by the United States Government or any agency thereof. The views and opinions of authors expressed herein do not necessarily state or reflect those of the United States Government or any agency thereof.
} 

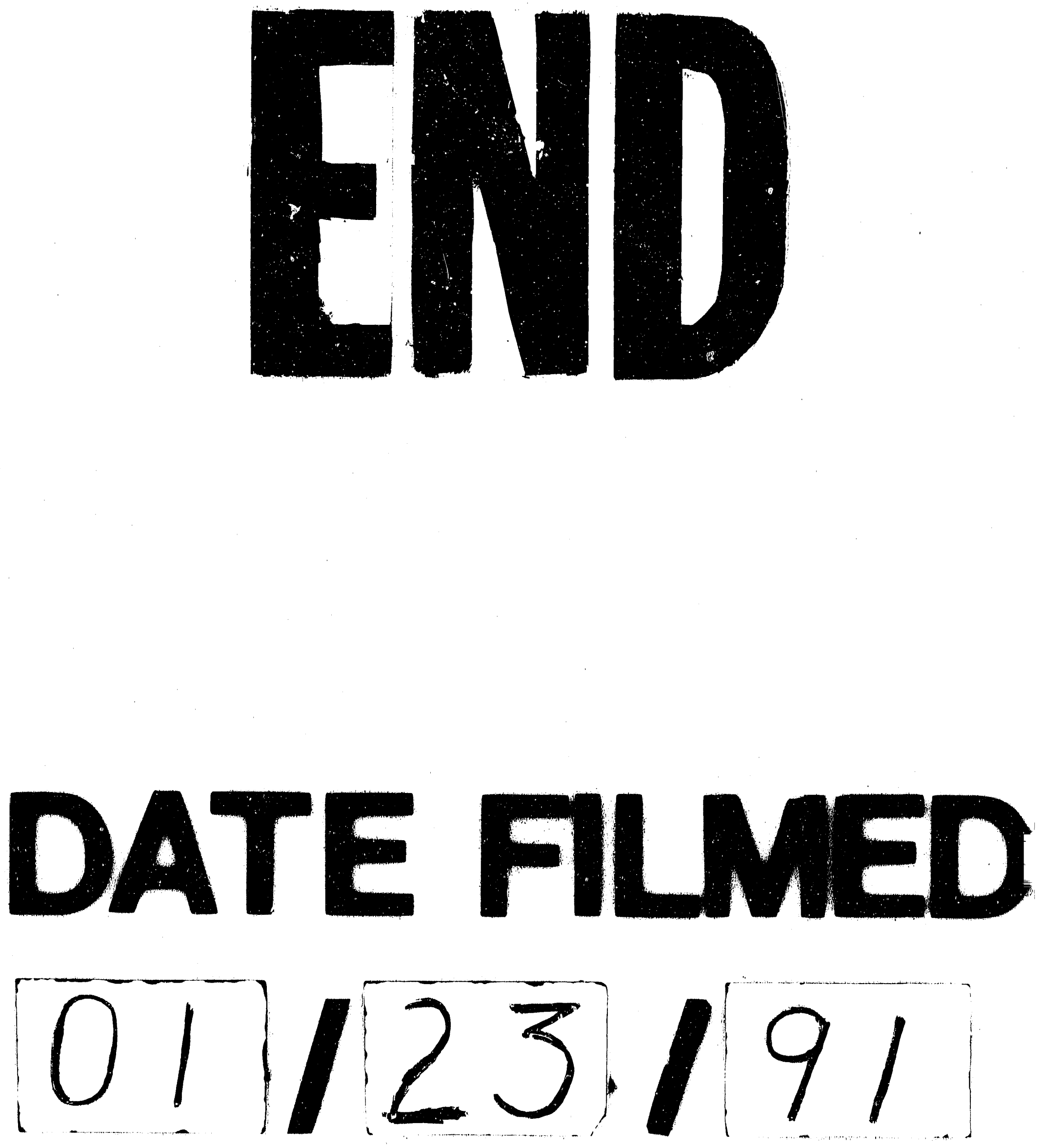
